\title{
CuO Coated Electrochemically Generated Textile Wastewater Sludge and CuO Coated GAC as Potential Nano-adsorbents for Color Removal from Real Textile Wastewater
}

\author{
SRIKANTHA ${ }^{1 *}$, MAHESH S and SAHANA $M^{2}$ \\ 'Department of Civil Engineering, Alva's Institute of Engineering and Technology, Moodbidri, Mijar, \\ Dakshina Kannada, Karnataka, India. \\ ${ }^{2}$ Department of Environmental Engineering, Sri Jayachamarajendra College of Engineering \\ (JSS S\&T University), Mysuru, Karnataka, India. \\ *Corresponding author E-mail: sriki.env@gmail.com \\ http://dx.doi.org/10.13005/ojc/3404056
}

(Received: July 20, 2018; Accepted: August 01, 2018)

\begin{abstract}
A laboratory scale setup was used to remove color from real textile wastewater (TWW) using nano $\mathrm{CuO}$ coated electrochemically generated sludge and nano $\mathrm{CuO}$ coated GAC. ECC studies were conducted in batch-mode to generate sludge treating real TWW using pre-optimized 4SS electrodes using a $1.5 \mathrm{~L}$ reactor operated at cell voltage of $18 \mathrm{~V}$ and current density $180 \mathrm{~A} / \mathrm{m}^{2}$ at an agitation speed of $500 \mathrm{rpm}$ for $60 \mathrm{~min}$. electrolysis time. SEM, FTIR and XRD analysis confirmed CuO material successfully coated/decorated on electrochemically generated sludge of size $\sim 0.3-0.5 \mathrm{~mm}$ and GAC of size $\sim 0.5 \mathrm{~mm}$. To check the color removal efficiencies from TWW the batch adsorption studies were conducted for adsorbent dose, stirring time and $\mathrm{pH}$. The optimal operating conditions achieved at $\mathrm{pH}-4$, dose of $0.6 \mathrm{~g} / \mathrm{L}$ and $30 \mathrm{~min}$. contact time for CuO-sludge nano-adsorbent achieving $50-55 \%$ color removal. Similarly, for CuO-GAC nano-adsorbent the optimal conditions obtained at
\end{abstract}

\section{INTRODUCTION}

Nanomaterials and its application in wastewater treatment is widely used for has gained accelerated clean water reclamation. Materials at nano scale, often possess novel size-dependent properties different from their large counterparts ${ }^{2}$ and with additional substrate its performance is very high.

The water environment is globally being polluted by organic dyes mainly discharged from textile ${ }^{3}$, paper and pulp ${ }^{4-6}$, printing, leather pigmentation, dyestuff, plastic and other such industries. It is estimated that about $10-20 \%$ of dyes are wasted upon complete utilization in the dyeing unit with $\sim 125-150 \mathrm{~L}$ of water used for $1 \mathrm{~kg}$ of textile produced. The dyeing process releases huge quantities of wastewater ${ }^{7}$. Wastewater treatment units in the textile industry use several thousands of meter cubes of water every day ${ }^{8}$. High levels

This is an Open Access article licensed under a Creative Commons Attribution-Non Commercial-Share Alike 4.0 International License (https://creativecommons.org/licenses/by-nc-sa/4.0/), which permits unrestricted Non Commercial use, distribution and reproduction in any medium, provided the original work is properly cited. 
of chemical oxygen demand (COD), burly color, dissolved solids, highly fluctuating $\mathrm{pH}$, recalcitrancy and poor biological degradation make textile industry wastewaters tough, carcinogenic and toxic to aquatic species $^{9,10}$.

In the past, adsorption using granular activated carbon (GAC) was considered effective, versatile and economical for wastewater treatment. Its features such as high removal efficiency, simple process, low operational cost and easy functional modifications endow potential for adsorptionbased water treatment applications. Researchers have shown the use of materials like walnut husk, composites, biochars from crop residues, natural clinoptilolite, sesame hull, biomass of penicillium, natural zeolite, cross-linked succinyl chitosan, modified bentonite, modified attapulgite, clay material, activated carbon, dehydrated beet pulp carbon, polyurethane foam, etc. as adsorbents for the removal of dyes from wastewater ${ }^{11}$. Much attention is now in focus for the use of nanotechnology for wastewater treatment to reduce the adsorbent dosage on a large scale using a combination of substrate alternate to GAC and nanocoating on it. In recent years, with the development of nano-technology various nanomaterials is extensively used in adsorption including graphene, graphene oxide, carbon nanotubes (CNTs), etc ${ }^{12}$. Metal oxide (MO) nano-particles have various practical applications because of their unique physical and chemical properties that improve adsorptive characteristics over a substrate.

Copper oxide nano-particles with large surface areas and potential size effects the physical and chemical properties that remarkably differ from those of their micro or bulk counterparts. Recent studies have demonstrated that nanoscale $\mathrm{CuO}$ can be used to prepare various organic and inorganic nanocomposites with high thermal conductivity, electrical conductivity, mechanical strength and temperature durability ${ }^{13}$. Compared with other $\mathrm{MO}$ nanostructures such as $\mathrm{TiO}_{2}, \mathrm{ZnO}$ and $\mathrm{SnO}_{2}$, $\mathrm{CuO}$ nanoparticles have more magnetic and super-hydrophobic properties. With these unique properties, $\mathrm{CuO}$ can be used over a hard substrate like sludge with nano-coatings to enhance the three sequential steps in the adsorption process - film diffusion, intra-particle diffusion and pore diffusion.
The substrate in the present work is chosen to be an electrochemically generated sludge treating textile wastewater as a replacement to the traditional GAC.

In general, sludge generated from textile industries is a surplus waste material in wastewater treatment facilities and its disposal is observed as a serious environmental concern. The excruciating environmental significance of disposing textile industry waste sludge in landfills causes intoxication of groundwater by long-term leachate. The utilization of sludge in wastewater treatment facilities as an adsorbent replacing GAC seem to a useful option in tertiary treatment to remove residual color. For this idea to take effect, raw textile wastewater stream was treated using the novel electrochemical coagulation (ECC) as a best treatment option with a shortest retention time (HRT) of 60-75 min. using stainless steel (SS) electrodes for a pre-set surface area by volume (SA/V) ratio. The ECC sludge obtained were metal based sturdy/hard comparable with GAC to be used as a substrate with suitable nano-coating/decoration on it to initiate tertiary treatment. Therefore, the objective was set to check the feasibility of removing color from the textile wastewaters using Copper oxide nano-adsorbents coated/decorated by $\mathrm{CuO}$ nano-particles on electrochemically treated sludge and on GAC.

\section{MATERIALS AND METHODS}

The chemicals - cupric nitrate trihydrate, oxalic dihydrazine $(\mathrm{ODH})$ used for preparing $\mathrm{CuO}$ nanoparticles were of analytical reagent (AR) grade purchased from Himedia Laboratories, Mumbai, India. The granular activated carbon (GAC) of size $0.5 \mathrm{~mm}$ were used as a base material for coating purchased from Mumbai, India. The electrochemical sludge as another hard substrate was obtained from the scum after treating real textile wastewater using ECC with SS electrodes in a bipolar electrode arrangement.

\section{Batch electrochemical coagulation studies}

Batch electrochemical coagulation (ECC) studies were composed to generate sludge treating real TWW using pre-optimized four stainless steel electrodes giving SA $/ V$ of $20 \mathrm{~m}^{2} / \mathrm{m}^{3}$. The batch ECC process was carried out for operating conditions such as voltage, current density, and electrolysis time 
(ET). All the experiments were carried out in a batch electrochemical coagulation (BECC) reactor with 1.5 $L$ of effective capacity, operated at cell voltage of $18 \mathrm{~V}$, current density $180 \mathrm{~A} / \mathrm{m}^{2}$ at an agitation speed of $500 \mathrm{rpm}$ for $60 \mathrm{~min}$. ET. The wastewater is then allowed to settle in a settling column for $30 \mathrm{~min}$. where sludge is settled at the bottom and the supernatant at the top of the settling column. The supernatant is decanted easily and the sludge/slurry is collected in a separate glass beaker. This wet sludge was kept in a hot air oven at $105^{\circ} \mathrm{C}$ for $24 \mathrm{~h}$ cooled down to room temperature and stored in the polymer sachets for further studies by decorating with nano-particles. Repeated BECC experiments were carried out to generate sufficient quantity of dry sludge for using it as substrate for $\mathrm{CuO}$ nano-coating on it.

\section{Synthesis of copper oxide nanoparticles}

The copper oxide nanoparticles were prepared using 'Iow temperature combustion' method. The redox mixture of cupric nitrate trihydrate and $\mathrm{ODH}$ were mixed in stoichiometric proportions using the total oxidizing and reducing valencies of the reactants so that the equivalent ratios of Fuel and Oxidizer is unity $(\mathrm{F} / \mathrm{O}=1)$ and the energy released during the combustion process is maximum.

$15.18 \mathrm{~g} \mathrm{Cu}\left(\mathrm{NO}_{3}\right) 2 \bullet_{3} \mathrm{H}_{2} \mathrm{O}$ and $7.414 \mathrm{~g} \mathrm{ODH}$ is mixed with 50-60 ml distilled water and stirred for $1 \mathrm{~h}$ till the crystals dissolved completely and this mixture was subject to rapid heating and combustion in a muffle furnace at $400^{\circ} \mathrm{C}$. The material obtained was washed and subject to check its stability washing with $5 \%$ dilute acid $(\mathrm{HCl})$ and base $(\mathrm{NaOH})$. The synthesis of $\mathrm{CuO}$ particles using combustion method is described stoichiometrically in Fig. 1 and the reaction that takes place is shown in equation (1).

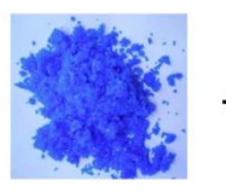

$\mathrm{Cu}\left(\mathrm{NO}_{3}\right)_{2} \cdot 3 \mathrm{H}_{2} \mathrm{O}$

(2.41g)

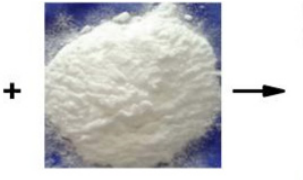

$\mathrm{ODH} \mathrm{C}{ }_{2} \mathrm{H}_{6} \mathrm{~N}_{4} \mathrm{O}_{2}$ (1.18g)

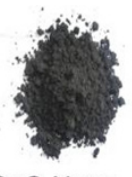

CuO Nano adorsorbent $(0.3248 \mathrm{~g})$
Fig. 1. Synthesized Copper oxide (CuO) by low temperature combustion

$5 \mathrm{Cu}\left(\mathrm{NO}_{3}\right)_{2}[\mathrm{aq}]+4 \mathrm{C}_{2} \quad \mathrm{~N}_{4} \mathrm{H}_{6} \mathrm{O}_{2}[\mathrm{aq}] \rightarrow 5 \mathrm{CuO}[\mathrm{s}]+8 \mathrm{CO}_{2}$ $[\mathrm{g}]+13 \mathrm{~N}_{2}[\mathrm{~g}]+12 \mathrm{H}_{2} \mathrm{O}$

CuO nanoparticle coating on ECC generated textile wastewater sludge and GAC

The obtained nanomaterial/nano-adsorbent is coated on the electrochemically generated TWW sludge of size 0.3-0.5 mm and GAC samples of size $0.5 \mathrm{~mm}$. The nano-adsorbent was coated by adding $1 \mathrm{mg}$ of $\mathrm{CuO}$ nano-adsorbent to $0.1,0.2,0.3,0.4$ $0.5,0.6,0.7,0.8$ and $0.9 \mathrm{~g}$ of TWW sludge samples followed by $0.1,0.2,0.3,0.40 .5,0.6,0.7,0.8$ and $0.9 \mathrm{~g}$ of GAC samples (with a total of 18 samples).

The CuO nanoparticle with sludges and GACs samples (9 sludge and 9 GAC dosage) were stirred separately with $20 \mathrm{ml}$ deionized water for $3 \mathrm{~h}$ keeping the temperature $<15^{\circ} \mathrm{C}$. The mixture was again blended for $1 \mathrm{~h}$ at room temperature of $25-30{ }^{\circ} \mathrm{C}$ until it shows pasty slime like appearance. Further, the mixture was refluxed at $50{ }^{\circ} \mathrm{C}$ for 15 min. and stirred for $1 \mathrm{~h}$ at $25^{\circ} \mathrm{C}$ to coat nanoparticles on the two substrates. The coated mixtures was washed by repeated centrifugation with $10 \% \mathrm{HCl}$ solution followed by deionized water until the $\mathrm{pH}$ of the solution becomes neutral and the same was sonicated. Finally, the $\mathrm{CuO}$-sludge and $\mathrm{CuO}-\mathrm{GAC}$ mixtures were dried at $70^{\circ} \mathrm{C}$ in hot air oven for $24 \mathrm{~h}$ to get nano-coated substrates. The characterization of the prepared $\mathrm{CuO}$ nano-coated substrates were confirmed using Scanning Electron Microscope (SEM) by SU3500, Hitachi, Japan; Powder X-Ray Diffraction (PXRD) by Microstar Proteum 8, Bruker; and Fourier Transform infrared Spectroscopy (FTIR) by FT/IR 460 plus, Jasco.

\section{Batch adsorption studies}

In the batch studies, experiments were conducted with $\mathrm{CuO}$ nano-coated substrates for the color removal picking a real TWW stream from a silk manufacturing industry. A systematic procedure was followed by taking $50 \mathrm{~mL}$ TWW in a $250 \mathrm{~mL}$ beaker and 0.1-0.9 g CuO nano-coated sludge and GAC samples were added. The mixture was stirred employing an inductive magnetic stirring unit the help of a magnetic bead setting the optimum stirring speed at $400 \mathrm{rpm}$ for a specific contact time of $30 \mathrm{~min}$. In all the cases, the solution was separated from the substrates by centrifugation at a speed of $2500 \mathrm{rpm}$ for 6 minute. The supernatant solution was collected in test tubes, and the absorbance was measured for each case. To check the removal efficiencies of color from TWW batch adsorption studies were carried out on three operational parameters - adsorbent dose, stirring time and $\mathrm{pH}$. 
Effect of adsorbent dosage: Adsorbent doses were varied from 0.1 to $0.9 \mathrm{~g}$ (9 samples each) and the stirring was kept up to 30 minute. The mixture was then centrifuged and the absorbance was measured.

Effect of stirring time: The optimal dosage was fixed from the dosage effect; the time of stirring was varied from 1 - $40 \mathrm{~min}$. followed by centrifugation and measurement of absorbance.

Effect of pH: Using the optimal dosage and stirring time, the $\mathrm{pH}$ of the solution was varied from 4-7.5. After a series of batch experiments, the optimal adsorbent dosage, contact time (CT) and $\mathrm{pH}$ was obtained. The color removal efficiency was assessed using the equation (2).

Color removal $(\%)=\frac{A b s_{0}-A b s_{f}}{A b s_{0}} \times 100$

Where, Abso is the initial absorbance at optical density 1.0 and Absf is the absorbance after the batch adsorption process.

\section{Characteristics of raw textile wastewater}

Raw TWW for use in batch ECC treatment was collected from a dye stream outfall conduit discharging in to the equalization basin of a local silk textile manufacturing industry and immediately characterized for various physico-chemical water quality parameters in duplicate without preservation using procedures accorded in Standard methods for analysis of wastewater ${ }^{14}$. The initial characteristics of raw TWW used in the Batch ECC are shown in Table 1.

Table 1: Characteristics of Raw Silk Textile Wastewater

\begin{tabular}{lcc}
\hline Parameters & Unit & Values \\
\hline $\mathrm{pH}$ & - & $5.40-5.61$ \\
Electrical Conductivity & $\mu \mathrm{ss} / \mathrm{cm}$ & $2680-2708$ \\
Color & absorbance & $0.7737-0.8546$ \\
$\mathrm{COD}$ & $\mathrm{mg} / \mathrm{L}$ & $2400-2700$ \\
Total hardness & $\mathrm{mg} / \mathrm{L}$ & $110-130$ \\
Calcium hardness & $\mathrm{mg} / \mathrm{L}$ & $80-90$ \\
Magnesium hardness & $\mathrm{mg} / \mathrm{L}$ & $30-40$ \\
Total Alkalinity & $\mathrm{mg} / \mathrm{L}$ & $20-28$ \\
Chloride & $\mathrm{mg} / \mathrm{L}$ & $760-840$ \\
Nitrate & $\mathrm{mg} / \mathrm{L}$ & $155-170$ \\
Phosphate & $\mathrm{mg} / \mathrm{L}$ & $245-262$ \\
Sulphate & $\mathrm{mg} / \mathrm{L}$ & $198-213$ \\
\hline
\end{tabular}

\section{RESULTS AND DISCUSSION}

The physical and chemical properties of electrochemically generated sludge were determined using standard methods ${ }^{15}$. The $\mathrm{pH}$ value of sludge was alkaline in nature having $\mathrm{pH} 8.14-8.60$. The specific gravity and bulk density of ECC sludge were 1.05 and $2128 \mathrm{~kg} / \mathrm{m}^{3}$ respectively. The volatile solids in TWW ECC sludge was $72 \%$ and the fixed solids content $19.08 \%$. The electrochemical (EC) sludge had low moisture content of $2.81 \%$ and ash $50.21 \%$.

\section{Confirmation of $\mathrm{CuO}$ nano-adsorbent}

A mixture of weighed amount of cupric nitrate trihydrate and oxalic dihydrazine (ODH) dissolved in distilled water was subjected to rapid heating in a muffle furnace at $400^{\circ} \mathrm{C}$. During the combustion process, the reaction is exothermic and the energy released in the form of heat forming products like $\mathrm{CuO}, \mathrm{CO}_{2}, \mathrm{~N}_{2}$ and $\mathrm{H}_{2} \mathrm{O}$. After complete combustion, a black colored powder like material is obtained. The powder like material was characterized for SEM, FTIR and XRD analysis. The images confirmed that the powder obtained were $\mathrm{CuO}$ nanoparticles. Fig. 2 (a) shows the SEM image of CuO nanoparticles, Fig. 2 (b) shows FTIR and Fig. 2 (c) shows XRD of $\mathrm{CuO}$ nanoparticles.

The SEM image (Fig. 2(a)) at 10000X magnification shows surface morphology with particle attached forming agglomerates because of high temperature exposure during combustion. The product so formed is porous and comprised of large void spaces as interpreted from the SEM image. The by-products $\mathrm{CO}_{2}, \mathrm{~N}$ and $\mathrm{H}$ atoms escape through the synthesized material resulting in high voids and porosity in the product obtained.

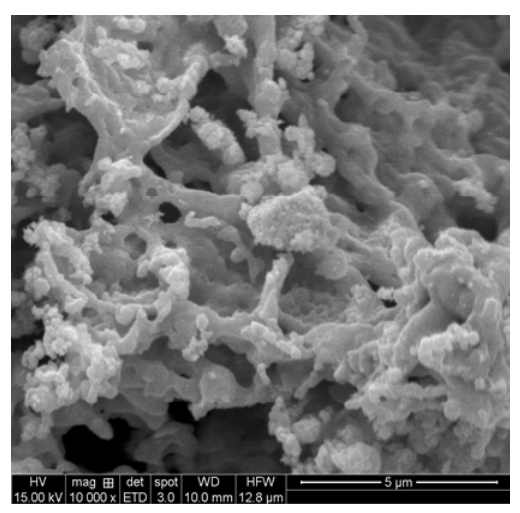

Fig. 2 (a). SEM image of Copper oxide (CuO) nano-particles 
The FTIR spectrum in Fig. 2 (b) shows the absorption bands at 490,1500 and $3400 \mathrm{~cm}^{-1}$. The peak around $524 \mathrm{~cm}^{-1}$ is assigned to the vibrations of $\mathrm{CuO}$ and gives information about the effective bond formations. The principle substance used for the $\mathrm{CuO}$ nano-material synthesis was cupric nitrate trihydrate, and therefore the band around $1500 \mathrm{~cm}^{-1}$ is assigned to traces of nitrate content present in the product. The widened peak at $3700 \mathrm{~cm}^{-1}$ is attributed to $\mathrm{H}-\mathrm{O}-\mathrm{H}$ stretching vibrations of the adsorbed water.

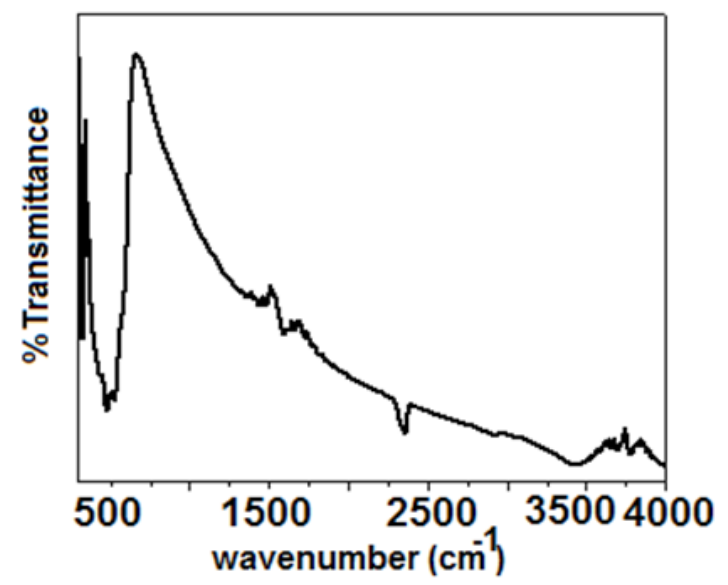

Fig. 2 (b) FTIR of CuO nano-particles

Figure 2 (c) shows X-RD pattern for $\mathrm{CuO}$ nano-particles. The XRD unit was operated with a goniometer speed of $5.000 \mathrm{deg} . / \mathrm{min}$. with a scan range of $0-60$ on the abscissa. The Powdered XRD patterns of $\mathrm{CuO}$ confirms with the pattern of the Joint Committee on Power Diffraction Standards (JCPDS 140164). The higher peaks denote crystalline nature of the formed compound. Broader the width of the frequencies lesser is the particle size crystallites.

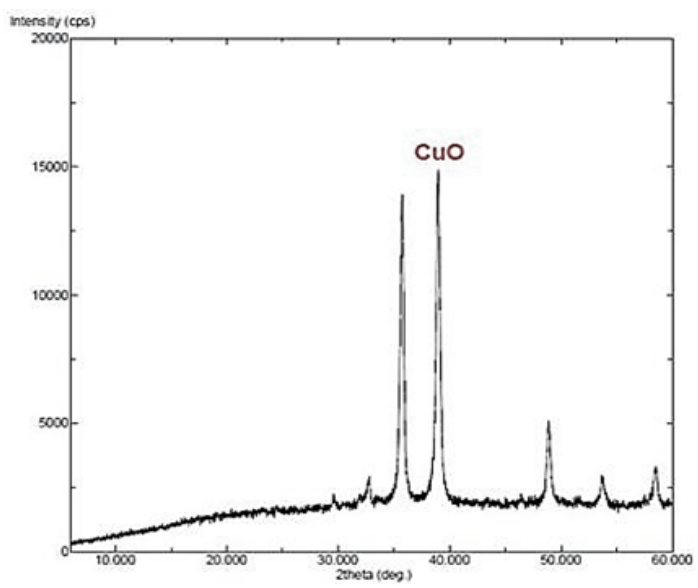

Fig. 2 (c) X-Ray diffractogram for CuO nano-particles
Figure 2 SEM image of copper oxide nano-particles, FTIR of CuO nano-particles, X-Ray diffractogram for $\mathrm{CuO}$ nano-particles

The estimation of particle sizes of the crystallites from the XRD graphs are briefly described as follows. The particle size analysis is evaluated using the Scherrer's formula as given in equation (3) assuming particle morphology as spherical.

$D=k \lambda / \beta \operatorname{Cos} \theta$

Where, $D$ is the diameter of crystallite size, $\beta$ is Full Width at Half Maximum (FWHM in rad), $\lambda$ is the wavelength of $X$-rays, $\theta$ is the diffraction angle, and $\mathrm{k}$ is the Scherrer's constant.

For estimation of the crystalline size using Scherrer's formula, one peak preferably between $38^{\circ}$ and $40^{\circ}$ is selected and the width half value of its maximum intensity is determined. This is called Full Width at Half Maximum (FWHM).

$\mathrm{FWHM}=\theta_{2}-\theta_{1}$

Here, $\theta 2=39.158$ and $\theta_{1}=38.715$

$\beta=\left(\theta_{2}-\theta_{1}\right) \times \pi / 180 \rightarrow \beta=0.0077 \mathrm{rad}$.

$2 \theta=38.90$

$\lambda=1.54 \mathrm{Ao}=1.54 \times 10-10 \mathrm{~m}$

The $k$ values is 0.94 for FWHM of spherical crystals with cubic symmetry, 0.89 for integral breadth of spherical crystals without cubical symmetry, 1.03 for tetrahedral crystallites (100) peak and 0.81 for octahedral crystallites (100) peak. Applying the $\mathrm{k}$ values in the Scherrer's formula, the size of $\mathrm{CuO}$ nano-adsorbent was estimated to be $19.027 \times 10^{-9}$ $\mathrm{m}$ or $19.027 \mathrm{~nm}$. In addition, it may be seen from the Fig. 2 (c) that the plot confirms the formation of nano-particles.

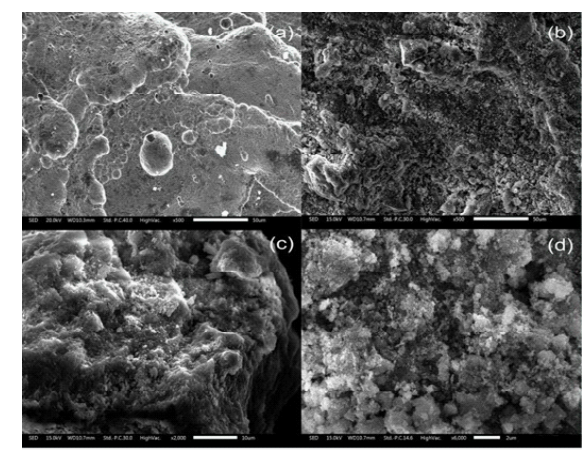

Fig. 3 SEM image of substrates (GAC and ECC sludge) before and after Copper oxide (CuO) nano-coating 
Surface morphology of sludge, GAC and nano-coated substrates

To confirm the coating/decorating of $\mathrm{CuO}$ nanoparticles on the sludge and GAC morphological analysis was carried out on these coated substrates using SEM. The surface of the sludge and GAC substrates is shown in Fig. 3 before and after nanocoating. Fig. 3 (a) and (b) shows electrochemically treated sludge before and after the $\mathrm{CuO}$ nanocoating. Similarly, Fig. 3 (c) and (d) shows GAC before and after nano-coating. From Fig. 3 (b) and (d) it may be observed that the $\mathrm{CuO}$ nano-adsorbent is completely coated on to both the substrates successfully.

\section{Batch adsorption studies}

Batch experimental adsorption studies were conducted to arrive at the optimal operating conditions for the color removal from real TWW. Batch adsorption were conducted for the effect of adsorbent doses, effect of stirring/contact time and the effect of $\mathrm{pH}$. Adsorption equations could not be used because real textile wastewater stream were used to evaluate color removals because of its inherent heterogeneity.

\section{Effect of adsorbent dose}

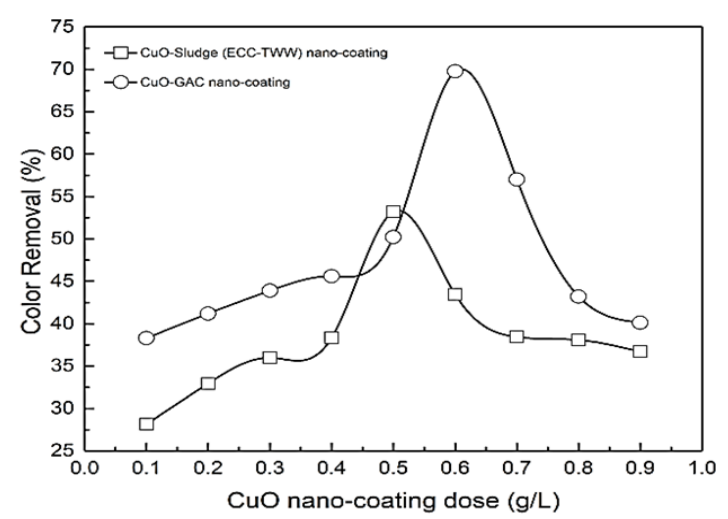

Fig. 4. Effect of CuO-sludge and CuO-GAC doses on color removal from real TWW

Operating conditions: $\mathrm{pH}$ : 5.99; agitation speed: 400 rpm; stirring time: $30 \mathrm{~min}$. for real TWW Fig. 4 shows color removal as a function of $\mathrm{CuO}$ nanoadsorbent dose for the said operating conditions. $\mathrm{CuO}$ nano-adsorbent substrate dose was varied from 0.1-0.9 g per liter of the bulk solution. As observed from the curves, color removal of $53 \%$ was obtained at the adsorbent dose of $0.6 \mathrm{~g} / \mathrm{L}$ for CuO-sludge substrate. Similarly, color removal of $69 \%$ was obtained at the adsorbent dose of $0.5 \mathrm{~g} / \mathrm{L}$ for CuO-GAC substrate. At lower adsorbent doses, number of active sites is higher and with the increase in adsorbent dose, aggregation of particles take place as a result of which removal efficiency increases ${ }^{16}$. Lower and higher adsorbent doses showed lesser color removal from the bulk solution. An overall improvement of $\sim 16 \%$ color removal was achieved while using CuO-GAC substrate for reasons ascribed to the presence of other organics in real TWW.

\section{Effect of stirring/contact time}

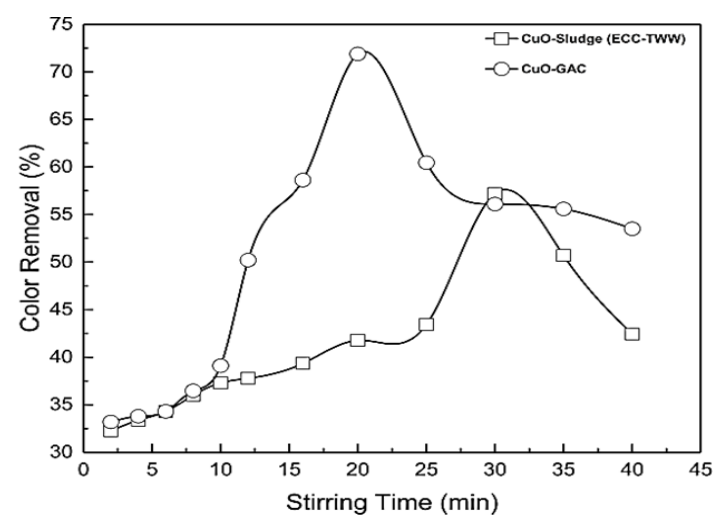

Fig. 5. Effect of stirring time on removal of color from $\mathrm{CuO}$ sludge and CuO-GAC

Operating conditions: $\mathrm{pH} 0$ : 5.99; agitation speed: $400 \mathrm{rpm}$; stirring time: $40 \mathrm{~min}$ for real TWW Fig. 5 shows color removal as a function of stirring/ contact time for the operating conditions: pHo 5.99; agitation speed of $400 \mathrm{rpm}$, CuO-sludge dose of $0.5 \mathrm{~g} / \mathrm{L}, 0.6 \mathrm{~g} / \mathrm{L}$ for CuO-GAC and the stirring time was varied from 1-40 min. From Fig. 5 it may be seen that maximum color removal of $57 \%$ was achieved for a stirring time $30 \mathrm{~min}$. for CuO-sludge and similarly, maximum color removal of $72 \%$ was obtained at $20 \mathrm{~min}$ stirring time for CuO-GAC nano-adsorbent. Lower and higher stirring time showed comparatively low color removal from the bulk solution. An overall improvement of $\sim 15 \%$ color removal was achieved for the CuO-GAC substrate. Further increase in stirring time cause disintegration of both CuO nano-coated substrates and the removal efficiency reduced.

\section{Effect of $\mathrm{pH}$}

Figure 6 shows the color removal as a function of $\mathrm{pH}$ for the operating conditions. The $\mathrm{pH}$ was varied within a small bandwidth from 4-7.5 for 
TWW and the $\mathrm{pH}$ was adjusted using $5 \%$ dilute $\mathrm{HCl}$ and $\mathrm{NaOH}$. This $\mathrm{pH}$ band was selected because the real TWW streams in the textile industry ranged from 4.5-7.5. From the plot, we may observe that increase in $\mathrm{pH}$ showed reduction in color removal efficiency for both the substrates. It is surmised that as the $\mathrm{pH}$ of the bulk solution increase the surface of $\mathrm{CuO}$ nanoparticles become more negatively charged and repulsive effect occurs and so the removal efficiency decreases. Color removal was maximum in the acidic $\mathrm{pH}$ range between 4-4.5 for both $\mathrm{CuO}$-sludge and CuO-GAC substrates. A higher color removal was obtained for CuO-GAC compared to CuO-sludge nanoparticles.

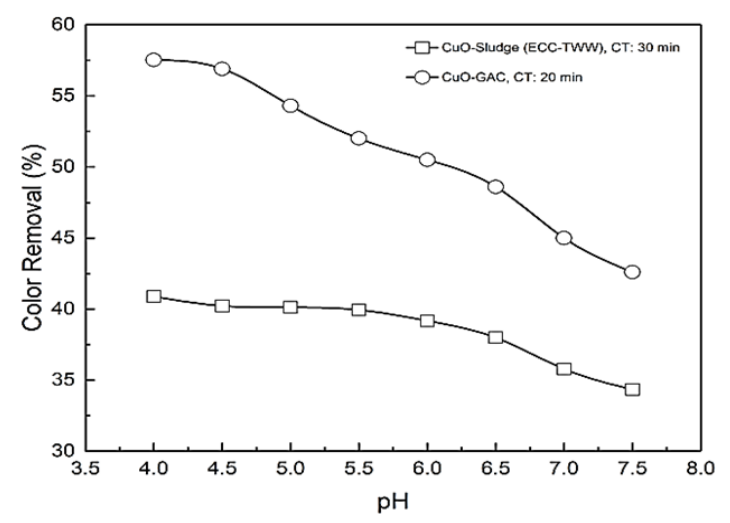

Fig. 6. Effect of pH on the removal of color from CuOsludge and CuO-GAC nano-coating substrates

Operating conditions: agitation speed: $400 \mathrm{rpm}$; $\mathrm{CuO}$ nano-coating substrate dose of $0.5 \mathrm{~g} / \mathrm{L}$ for CuO-sludge and $0.6 \mathrm{~g} / \mathrm{L}$ for CuO-GAC substrate, stirring time of $30 \mathrm{~min}$. and $20 \mathrm{~min}$. for real TWW (a) Raw TWW before and after adsorption with CuO coated ECC sludge (b) Raw TWW before and after adsorption with $\mathrm{CuO}$ coated GAC

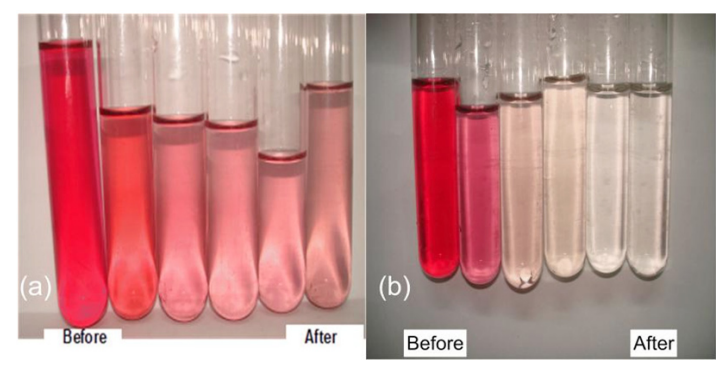

Fig. 7. Color removal by nano-adsorbent using CuO-sludge (ECC-TWW) and CuO-GAC substrates

Figure 7 (a) shows pictorial representations of color removal from real TWW during batch experiments for $\mathrm{CuO}$-sludge nano-coating substrates. The first test tube (LHS) shows raw TWW, while the second test tube shows $0.1 \mathrm{~g} / \mathrm{L} \mathrm{CuO-sludge} \mathrm{coated}$ nano-adsorbent after $30 \mathrm{~min}$. contact time. The remaining four tubes show color removals for 0.2, $0.3,0.4,0.5,0.6 \mathrm{~g} / \mathrm{L}$ of CuO coated sludge. Similarly, Fig. 7 (b) shows the color removal during adsorption experiments for GAC particle sizes of $\sim 0.5 \mathrm{~mm}$. The first test tube (LHS) shows raw TWW, while the second test tube shows $0.2 \mathrm{~g} / \mathrm{L} \mathrm{CuO} \mathrm{coated} \mathrm{GAC}$ after $20 \mathrm{~min}$. contact time. The remaining four tubes show color removals for $0.3,0.4,0.5$ and $0.6 \mathrm{~g} / \mathrm{L}$ of $\mathrm{CuO}$ coated GAC. It may be observed from Fig. 7 (b) that more or less $100 \%$ color removal was achieved while using CuO-GAC coated nano-adsorbent when using smaller particle sizes. This observation is in par with the research work by Perrich, 198117.

\section{Regeneration of CuO coated GAC}

Regeneration of an adsorbent is an important aspect of any adsorption process. Regeneration for CuO coated ECC sludge and $\mathrm{CuO}$ coated GAC was carried out after color was removed completely from the solution. The $\mathrm{CuO}$ coated ECC sludge and CuO coated GAC were tested for its ability to retain its structure in acidic and basic solutions with $\mathrm{pH}$ ranging from 4.5-7.5. The CuO-Sludge and CuO-GAC nanosorbents were washed with water adjusted to the above set $\mathrm{pH}$. It was seen that $\sim 10-13 \% \mathrm{CuO}$ was lost during the regeneration process in both substrates. The regenerated $\mathrm{CuO}$ coated ECC sludge and $\mathrm{CuO}$ coated GAC was again used in batch experiments to check again its adsorptive potential for color removal. A further reduction in color removal of $\sim 15 \%$ and $\sim 20 \%$ was obtained while using regenerated $\mathrm{CuO}$ coated ECC sludge and CuO coated GAC.

\section{CONCLUSION}

Copper oxide as nano-particles and its coating on adsorbents like electrochemically treated sludge from textile wastewater and GAC showed reasonably good potential for reducing color from textile wastewater. The synthesized CuO nano-particles was subjected to SEM, FTIR and PXRD. PXRD analysis confirmed the nano-structure of $\mathrm{CUO}$ and SEM showed the morphology of $\mathrm{CuO}$ nanoparticles, nanocoating of $\mathrm{CuO}$ on sludge and GAC substrates. A color removal of $57 \%$ was achieved for the CuO-sludge dose of $0.5 \mathrm{~g} / \mathrm{L}$ at stirring time $30 \mathrm{~min}$. and $72 \%$ removal was achieved for CuO-GAC 
dose of $0.6 \mathrm{~g} / \mathrm{L}$ at contact time of 20 minute. The increase in the $\mathrm{pH}$ of wastewater showed reduction in color removal efficiency while using both $\mathrm{CuO}$ nano-coated substrates. A $100 \%$ color removal was achieved when $0.6 \mathrm{~g} / \mathrm{L}$ of $\mathrm{CuO}$ coated GAC of size $\sim 0.5 \mathrm{~mm}$ was used as an adsorbent. Coating of GAC with $\mathrm{CuO}$ increased the color removal efficiency compared to $\mathrm{CuO}$ coated on ECC sludge. Therefore, recovery, recycle and reuse concepts can be used for the electrochemically treated sludge by coating $\mathrm{CuO}$ nanoparticle instead of dumping in to agricultural fields or incinerating the sludge in boilers.

The ECC generated sludge used as a nanosorbents can be eventually used as a potent alternative to conventional treatment methods. The novel CuO-sludge nanoparticles developed in this work indeed possessed better color removal efficiency, which can be particularly used for dyebased industries. This work is presumed to be an eye opener/useful in developing new adsorbents from sludges generated from treatment of different agri-based industries.

\section{ACKNOWLEDGMENT}

The authors are thankful to Sri Jayachamarajendra College of Engineering (JSS S \&T University), Mysuru for giving the opportunity to carry out this research work. Srikantha $\mathrm{H}$ is thankful for the AIET, Moodbidri and Ministry of Human Resource Development (MHRD), Government of India, University grant commission (UGC) for providing fellowship throughout the research work.

\section{REFERENCES}

1. Nirmala, I., Int. J. Eng. Res. Appl., 2014, 4, 9. 55-63.

2. Qu, X., Pedro, J. J., Alvarez., Li, Q., Water Res., 2013, 47, 3931-3946.

3. O'Neill, C,, Hawkes, F. R., Hawkes, D. L., Lourenco, N. D., Pinheiro, H. M., Delee, W. J., Chem. Technol. Biotechnol., 1999, 74, 1009-1018.

4. Mahesh, S., Prasad, B., Mall, I. D., Mishra, I. M., Ind. Eng. Chem. Res., 2006, 45, 2830-2839.

5. Mahesh, S,, Prasad, B., Mall, I. D., Mishra, I. M., Ind. Eng. Chem. Res., 2006, 45, 5766-5774.

6. Mahesh, S., Garg, K. K., Srivastava, V. C., Mishra, I. M., Prasad, B., Mall, I. D., RSC. Adv., 2016, 20, 16223-16233.

7. Moussavi, G., Mahmoudi, M., J. Haz. Mat 2009, 168, 806-812.

8. Govindan, K., Oren, Y., Noel, M., Sep. Purif. Technol., 2014, 133, 396-406.
9. Mall I. D., Srivastava V. C., Agarwal N. K., Mishra I. M., Colloids. Surf. A. Physicochem. Eng. Asp., 2005, 264, 17-28.

10. Singh, S., Srivastava, V. C., Mall, I. D., Int. J. Chem. React. Eng., 2013, 11, 1-16.

11. Zhu, H. Y., Jiang, R., Fu, Y. Q., Jiang, J. H., Xiao, L., Zeng, G. M., J. of Chem. Engg., 2011 258, 1337-1344.

12. Wang, P., Cao, M., Wang, C., Ao, Y., Hou, J., Qian, J., Appl. Surf. Sci., 2014, 290, 116-124.

13. Zhang, Q., Zhang, K., Xu, D., Yang, G., Huang, H., Nie, F., Liu, C., Yang, S., Prog. Mater. Sci., 2014, 60, 208-337.

14. Baird, R. B., Eaton, A. D., Rice, E.W., APHA., 2017.

15. IS 1350 (Part1), Bureau of Indian Standards., 1984, 1-28.

16. Padmavathy, K. S., Madhu, G., Haseena, P.V., Proc. Technol., 2016, 24, 585-594.

17. Perrich, J, R., CRC press, Inc., 1981, 96-98. 